\title{
Conventional risk prediction models fail to accurately predict mortality risk among patients with coronavirus disease 2019 in intensive care units: a difficult time to assess clinical severity and quality of care
}

\author{
Hideki Endo ${ }^{1,2^{*}}$, Hiroyuki Ohbe ${ }^{3}$, Junji Kumasawa ${ }^{4}$, Shigehiko Uchino ${ }^{5}$, Satoru Hashimoto ${ }^{6}$, Yoshitaka Aoki ${ }^{7}$, \\ Takehiko Asaga ${ }^{8}$, Eiji Hashiba ${ }^{9}$, Junji Hatakeyama ${ }^{10}$, Katsura Hayakawa ${ }^{11}$, Nao Ichihara ${ }^{1}$, Hiromasa Irie ${ }^{12}$, \\ Tatsuya Kawasaki ${ }^{13}$, Hiroshi Kurosawa ${ }^{14}$, Tomoyuki Nakamura ${ }^{15}$, Hiroshi Okamoto ${ }^{16}$, Hidenobu Shigemitsu ${ }^{17}$, \\ Shunsuke Takaki ${ }^{18}$, Kohei Takimoto ${ }^{19}$, Masatoshi Uchida ${ }^{20}$, Ryo Uchimido ${ }^{17}$ and Hiroaki Miyata ${ }^{2}$
}

\begin{abstract}
Since the start of the coronavirus disease 2019 (COVID-19) pandemic, it has remained unknown whether conventional risk prediction tools used in intensive care units are applicable to patients with COVID-19. Therefore, we assessed the performance of established risk prediction models using the Japanese Intensive Care database. Discrimination and calibration of the models were poor. Revised risk prediction models are needed to assess the clinical severity of COVID-19 patients and monitor healthcare quality in ICUs overwhelmed by patients with COVID-19.
\end{abstract}

Keywords: Coronavirus disease 2019, Risk of death, Intensive care unit, Risk prediction model, Quality improvement

Dear Editor,

Since the start of the coronavirus disease 2019 (COVID-19) pandemic, intensive care units (ICUs) worldwide have struggled to treat affected patients who require a completely different approach to treatment than other patients [1]. Although many severe cases are admitted to ICUs, it is unknown whether the conventional risk scoring systems that were developed for ICU patients

\footnotetext{
*Correspondence: hidendo-thk@umin.ac.jp

'Department of Healthcare Quality Assessment, Graduate School of Medicine, The University of Tokyo, 7-3-1 Hongo, Bunkyo-ku, Tokyo 113-8655, Japan

${ }^{2}$ Department of Health Policy and Management, School of Medicine, Keio University, 35 Shinanomachi, Shinjuku-ku, Tokyo 160-8582, Japan Full list of author information is available at the end of the article
}

can be applied to patients with COVID-19. With unknown predictive performance, healthcare professionals have faced difficulties in assessing the clinical severity of patients with COVID-19 and monitoring the quality of care in ICUs. New risk prediction models for COVID-19 patients have been developed [2], but most of these were not developed specifically for ICU patients, and it is unknown whether they perform as well in clinical practice as they did in the model development studies. It is also likely that overwhelmed ICUs lack the time to derive and validate novel risk scores. In such circumstances, ICUs must use conventional scoring systems, such as the Acute Physiology and Chronic Health Evaluation (APACHE) and Simplified Acute Physiology Score (SAPS). Several

(c) The Author(s). 2021 Open Access This article is licensed under a Creative Commons Attribution 4.0 International License, which permits use, sharing, adaptation, distribution and reproduction in any medium or format, as long as you give appropriate credit to the original author(s) and the source, provide a link to the Creative Commons licence, and indicate if changes were made. The images or other third party material in this article are included in the article's Creative Commons licence, unless indicated otherwise in a credit line to the material. If material is not included in the article's Creative Commons licence and your intended use is not permitted by statutory regulation or exceeds the permitted use, you will need to obtain permission directly from the copyright holder. To view a copy of this licence, visit http://creativecommons.org/licenses/by/4.0/ The Creative Commons Public Domain Dedication waiver (http://creativecommons.org/publicdomain/zero/1.0/) applies to the data made available in this article, unless otherwise stated in a credit line to the data. 
recent studies have used APACHE and SAPS to provide information on the clinical severity of COVID-19 [3-5]. However, very few reports have examined their validity of applying them to patients with COVID-19. One letter from the UK reported that APACHE II underestimated the risk of death, concluding that the risk scoring systems that were widely used before the pandemic were inappropriate for evaluating the clinical severity of COVID-19 [6]. In Japan, a research group recently developed the Japan Risk of Death (JROD), a prediction model that recalibrated the APACHE III-j model [7]. However, this model may show limited validity in patients with COVID-19 because it was developed using the data collected before the pandemic and it was designed for general use in ICUs. Therefore, we investigated whether conventional risk prediction models, such as APACHE II, SAPS II, APACHE III-j, and JROD, can be applied to patients with COVID-19 and determined their predictive performance.

We obtained data for confirmed cases of COVID-19 admitted between January 2020 and February 2021 from the Japanese Intensive Care Patient Database (JIPAD) [8]. We used JROD to predict mortality in the same way as in the previous study [7], but with a development period of January 2019 to December 2019. This was then applied to predict mortality in the study cohort and defined as $\mathrm{JROD}_{2019}$ predicted mortality. The predictive performances of APACHE II, SAPS II, APACHE III-j, and $\mathrm{JROD}_{2019}$ were assessed using the area under the receiver operating characteristic curves, Brier scores, Hosmer-Lemeshow tests, calibration plots, and standardized mortality ratios.

A total of 444 patients admitted to 40 ICUs in Japan were extracted from the JIPAD for analysis. The clinical characteristics of patients are shown in Table 1. The model performance statistics are presented in Table 2 and Fig. 1. Death at hospital discharge was recorded in 69 patients (15.5\%), which was less than half the mortality reported by Stephens et al., although the APACHE II scores were comparable [6]. Using JIPAD data, the APACHE II, SAPS II, and APACHE III-j models overestimated the risk of death, whereas JROD $_{2019}$ underestimated the risk. The discrimination and calibration of APACHE III-j and JROD were poor compared with those reported in the JROD development study [7]. Although the results are dissimilar to a previous report [6] in terms of the direction of estimated risk (i.e., overestimation/underestimation), we make the same conclusion that the risk models used before the pandemic are not suitable for patients with COVID-19. Of note, even $\mathrm{JROD}_{2019}$, a model that was developed to improve the predictive ability of APACHE III-j, displayed suboptimal predictive performance. Owing to the poor predictive performance, it is difficult to incorporate the predicted mortality calculated using these risk models in quality
Table 1 Clinical characteristics

\begin{tabular}{|c|c|}
\hline Characteristic & Value \\
\hline Number of patients & 444 \\
\hline \multicolumn{2}{|l|}{ Baseline characteristics } \\
\hline Age, years, median [IQR] & $68[58,74]$ \\
\hline Male (\%) & $342(77.0)$ \\
\hline Body mass index, $\mathrm{kg} / \mathrm{m}^{2}$, median $[\mathrm{IQR}]$ & $25[22,28]$ \\
\hline $\begin{array}{l}\text { Days from hospital admission to ICU admission, } \\
\text { median [IQR] }\end{array}$ & $0[0,1]$ \\
\hline \multicolumn{2}{|l|}{ Admission source (\%) } \\
\hline Emergency room & $141(31.8)$ \\
\hline Transfer from another hospital & $159(35.8)$ \\
\hline Ward & $129(29.1)$ \\
\hline Other & $15(3.4)$ \\
\hline APACHE II score, median [IQR] & $16[13,21]$ \\
\hline APACHE I| predicted mortality, mean \% (SD) & $29.8(19.7)$ \\
\hline SAPS II score, median [IQR] & $38[29,46]$ \\
\hline SAPS II predicted mortality, mean \% (SD) & $27.6(24.5)$ \\
\hline APACHE III score, median [IQR] & $61[46,79]$ \\
\hline APACHE III-j predicted mortality, mean \% (SD) & $28.5(23.7)$ \\
\hline JROD predicted mortality, mean \% (SD) & $13.5(16.6)$ \\
\hline \multicolumn{2}{|l|}{ Treatments } \\
\hline Renal replacement therapy (\%) & $61(13.7)$ \\
\hline Mechanical ventilation (\%) & $329(74.1)$ \\
\hline Extracorporeal membrane oxygenation (\%) & $41(9.2)$ \\
\hline \multicolumn{2}{|l|}{ Outcomes } \\
\hline Death at ICU discharge (\%) & $47(10.6)$ \\
\hline Length of ICU stay, days, median [IQR] & $9[4,17]$ \\
\hline Death at hospital discharge (\%) & $69(15.5)$ \\
\hline Length of hospital stay, days, median [IQR] & $21[12,33]$ \\
\hline
\end{tabular}

APACHE Acute Physiology and Chronic Health Evaluation, ICU intensive care unit, IQR interquartile range, JROD Japan Risk of Death, SAPS Simplified Acute Physiology Score, SD standard deviation

Table 2 Model performance statistics

\begin{tabular}{|c|c|c|c|c|}
\hline & APACHE II & SAPS II & APACHE III-j & $\mathrm{JROD}_{2019}$ \\
\hline AUROC (95\% Cl) & $\begin{array}{l}0.704 \\
(0.634-0.774)\end{array}$ & $\begin{array}{l}0.696 \\
(0.627-0.765)\end{array}$ & $\begin{array}{l}0.707 \\
(0.642-0.772)\end{array}$ & $\begin{array}{l}0.718 \\
(0.654-0.782)\end{array}$ \\
\hline $\begin{array}{l}\text { Brier score } \\
(95 \% \mathrm{Cl})\end{array}$ & $\begin{array}{l}0.144 \\
(0.125-0.163)\end{array}$ & $\begin{array}{l}0.156 \\
(0.125-0.163)\end{array}$ & $\begin{array}{l}0.155 \\
(0.137-0.174)\end{array}$ & $\begin{array}{l}0.121 \\
(0.104-0.139)\end{array}$ \\
\hline $\begin{array}{l}\text { Hosmer-Lemeshow } \\
\text { test, } p \text { value }\end{array}$ & $<0.001$ & $<0.001$ & $<0.001$ & $<0.001$ \\
\hline \multicolumn{5}{|l|}{ Calibration plot } \\
\hline Slope & 0.782 & 0.472 & 0.548 & 0.587 \\
\hline Intercept & -1.124 & -1.257 & -1.231 & -0.452 \\
\hline $\begin{array}{l}\text { Standardized } \\
\text { mortality ratio } \\
(95 \% \text { Cl) }\end{array}$ & $\begin{array}{l}0.521 \\
(0.406-0.660)\end{array}$ & $\begin{array}{l}0.564 \\
(0.438-0.713)\end{array}$ & $\begin{array}{l}0.546 \\
(0.424-0.690)\end{array}$ & $\begin{array}{l}1.151 \\
(0.895-1.456)\end{array}$ \\
\hline
\end{tabular}

APACHE Acute Physiology and Chronic Health Evaluation, AUROC area under the receiver operating characteristic curve, $\mathrm{Cl}$ confidence interval, JROD Japan Risk of Death, SAPS Simplified Acute Physiology Score 


\section{APACHE II}

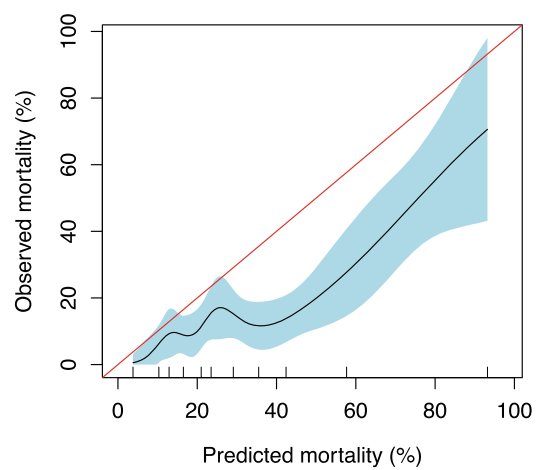

APACHE III-j

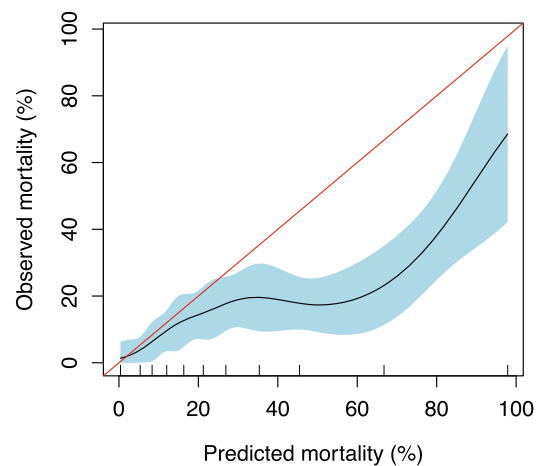

SAPS ॥

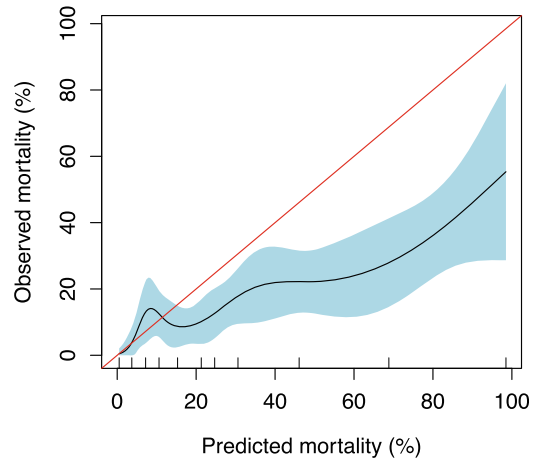

$\mathrm{JROD}_{2019}$

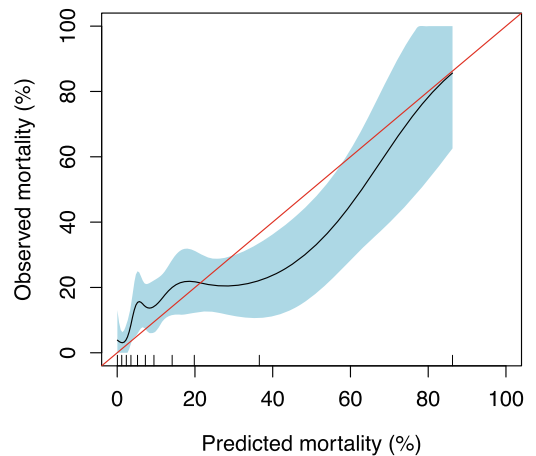

Fig. 1 Calibration plots. APACHE, Acute Physiology and Chronic Health Evaluation; JROD, Japan Risk of Death; SAPS, Simplified Acute Physiology Score. Note: Observed mortality is plotted against predicted mortality. The study population was divided according to the predicted mortality into 10 equally sized groups, which are presented as a rug plot along the horizontal axis. A natural spline was drawn for the plots. The shaded area indicates the $95 \%$ confidence interval. If the calibration is perfect, the plot aligns with the diagonal line

assessment tools, such as funnel plots and exponentially weighted moving average charts, with high reliability. Consequently, it will be difficult to implement quality assessment and improvement in ICUs, particularly those where patients with COVID-19 occupy a high proportion of ICU beds. Calibration can be improved with simple update methods, like that done in the JROD study, but discrimination can only be improved by updating the coefficients of each predictor and/or adding other relevant predictors [9]. Thus, a revised risk prediction model designed specifically for COVID-19 patients together with logistical support for its implementation in ICUs are urgently needed.

\section{Abbreviations}

APACHE: Acute Physiology and Chronic Health Evaluation; COVID19: Coronavirus disease 2019; ICU: Intensive care unit; JPAD: Japanese Intensive Care Patient Database; JROD: Japan Risk of Death; SAPS: Simplified Acute Physiology Score

\section{Acknowledgements}

We would like to thank all of the hospitals participating in the JIPAD for their contribution.
Authors' contributions

$\mathrm{HE}, \mathrm{HO}$, and JK conceived and designed the study. HE analyzed the data, interpreted the results, and wrote the first draft of the manuscript. SU, JH, KH, $\mathrm{HI}, \mathrm{JK}, \mathrm{HK}, \mathrm{TN}$, and $\mathrm{MU}$ contributed to data collection and ensured data credibility. YA, TA, EH, SH, JH, KH, NI, HI, TK, JK, HK, HM, TN, HO, HO, HS, TT, ST, $\mathrm{KT}, \mathrm{MU}, \mathrm{RU}$, and $\mathrm{SU}$ contributed to the interpretation of the results and revision of the manuscript. SH organized the JPAD project. The authors read and approved the final version of the manuscript and agreed to its submission.

\section{Funding}

This paper was written as a part of the JIPAD project, which was funded by the Japanese Society of Intensive Care Medicine.

\section{Availability of data and materials}

The authors' agreement with the JIPAD project does not allow us to publish the data used for this manuscript or to share it with others.

\section{Declarations}

\section{Ethics approval and consent to participate}

This study was approved by the Research Ethics Committee of the University of Tokyo (Approval number: 2020242NI-(1)). Consent to participate was waived because of the anonymous nature of the data.

Consent for publication

Not applicable. 


\section{Competing interests}

$\mathrm{HE}, \mathrm{NI}$, and $\mathrm{HM}$ are affiliated with the Department of Healthcare Quality Assessment at the University of Tokyo. The department is a social collaboration department supported by grants from the National Clinical Database, Johnson \& Johnson K.K., and Nipro Corporation. The other authors do not have any competing interests to declare.

\section{Author details}

'Department of Healthcare Quality Assessment, Graduate School of Medicine, The University of Tokyo, 7-3-1 Hongo, Bunkyo-ku, Tokyo 113-8655, Japan. ${ }^{2}$ Department of Health Policy and Management, School of Medicine, Keio University, 35 Shinanomachi, Shinjuku-ku, Tokyo 160-8582, Japan. ${ }^{3}$ Department of Clinical Epidemiology and Health Economics, School of Public Health, The University of Tokyo, 7-3-1 Hongo, Bunkyo-ku, Tokyo 113-0033, Japan. ${ }^{4}$ Department of Critical Care Medicine, Sakai City Medical Center, 1-1-1 Ebaraji-cho, Nishi-ku, Sakai, Osaka 593-8304, Japan. ${ }^{5}$ Intensive Care Unit, The Jikei University School of Medicine, 3-19-18 Nishi-Shinbashi, Minato-ku, Tokyo 105-8471, Japan. ${ }^{6}$ Department of Anesthesiology and Intensive Care Medicine, Kyoto Prefectural University of Medicine, 465 Kaji-cho, Kawaramachi-Hirokoji, Kamigyo-ku, Kyoto 602-8566, Japan. ${ }^{7}$ Department of Anesthesiology and Intensive Care Medicine, Hamamatsu University School of Medicine, 1-20-1 Handayama, Higashi-ku, Hamamatsu, Shizuoka 431-3192, Japan. ${ }^{8}$ Intensive Care Unit, Kagawa University Hospital, 1750-1 Ikenobe, Miki-cho, Kita-gun, Kagawa 761-0793, Japan. ${ }^{9}$ Division of Intensive Care, Hirosaki University Hospital, 53 Honcho, Hirosaki, Aomori 036-8203, Japan. ${ }^{10}$ Department of Emergency and Critical Care Medicine, National Hospital Organization Tokyo Medical Center, 2-5-1, Higashigaoka, Meguro-ku, Tokyo 152-8902, Japan. ${ }^{11}$ Department of Emergency and Critical Care Medicine, Saitama Red Cross Hospital, 1-5 Shintoshin, Chuo-ku, Saitama 330-8553, Japan. ${ }^{12}$ Department of Anesthesiology, Kurashiki Central Hospital, 1-1-1 Miwa, Kurashiki, Okayama 710-8602, Japan. ${ }^{13}$ Department of Pediatric Critical Care, Shizuoka Children's Hospital, 860 Urushiyama, Aoi-ku, Shizuoka, Shizuoka 420-8660, Japan. ${ }^{14}$ Department of Pediatric Critical Care Medicine, Hyogo Prefectural Kobe Children's Hospital, 1-6-7 Minatojima Minamimachi, Chuo-ku, Kobe, Hyogo 650-0047, Japan. ${ }^{15}$ Department of Anesthesiology and Critical Care Medicine, Fujita Health University School of Medicine, 1-98 Dengakugakubo, Kutsukake-cho, Toyoake, Aichi 470-1192, Japan.

${ }^{16}$ Department of Critical Care Medicine, St. Luke's International Hospital, 9-1 Akashi-cho, Chuo-ku, Tokyo 104-8560, Japan. ${ }^{17}$ Department of Intensive Care Medicine, Graduate School of Medicine, Tokyo Medical and Dental University, 1-5-45 Yushima, Bunkyo-ku, Tokyo 113-8519, Japan. ${ }^{18}$ Department of Anesthesiology and Critical Care Medicine, Yokohama City University, 3-9 Fukuura, Kanazawa-ku, Yokohama, Kanagawa 236-0004, Japan. ${ }^{19}$ Department of Intensive Care Medicine, Kameda Medical Center, 929 Higashi-cho, Kamogawa, Chiba 296-8602, Japan. ${ }^{20}$ Department of Emergency and Critical Care Medicine, Dokkyo Medical University, 880 Kitakobayashi, Mibu-machi, Shimotsuga-gun, Tochigi 321-0293, Japan.

Received: 8 April 2021 Accepted: 25 May 2021

Published online: 01 June 2021

\section{References}

1. Ma X, Vervoort D. Critical care capacity during the COVID-19 pandemic: global availability of intensive care beds. J Crit Care. 2020;58:96-7. https:// doi.org/10.1016/j.jcrc.2020.04.012.

2. Wynants L, Van Calster B, Collins GS, Riley RD, Heinze G, Schuit E, et al. Prediction models for diagnosis and prognosis of covid-19 infection: systematic review and critical appraisal. BMJ. 2020;369:m1328. https://doi. org/10.1136/bmj.m1328.

3. Xie J, Wu W, Li S, Hu Y, Hu M, Li J, et al. Clinical characteristics and outcomes of critically ill patients with novel coronavirus infectious disease (COVID-19) in China: a retrospective multicenter study. Intensive Care Med. 2020;46(10):1863-72. https://doi.org/10.1007/s00134-020-06211-2.

4. Ferrando C, Mellado-Artigas R, Gea A, Arruti E, Aldecoa C, Bordell A, et al. Patient characteristics, clinical course and factors associated to ICU mortality in critically ill patients infected with SARS-CoV-2 in Spain: a prospective, cohort, multicentre study. Rev Esp Anestesiol Reanim. 2020;67(8):425-37. https://doi.org/10.1016/j.redar.2020.07.003.

5. COVID-ICU Group on behalf of the REVA Network and the COVID-ICU Investigators. Clinical characteristics and day-90 outcomes of 4244 critically ill adults with COVID-19: a prospective cohort study. Intensive Care Med 2021;47:60-73. https://doi.org/10.1007/s00134-020-06294-X.

6. Stephens JR, Stümpfle R, Patel P, Brett S, Broomhead R, Baharlo B, et al. Analysis of critical care severity of illness scoring systems in patients with coronavirus disease 2019: a retrospective analysis of three U.K. ICUs. Crit Care Med. 2021;49(1):e105-7. https://doi.org/10.1097/CCM. 0000000000004674

7. Endo H, Uchino S, Hashimoto S, Aoki Y, Hashiba E, Hatakeyama J, et al. Development and validation of the predictive risk of death model for adult patients admitted to intensive care units in Japan: an approach to improve the accuracy of healthcare quality measures. J Intensive Care. 2021;9(1):18. https://doi.org/10.1186/s40560-021-00533-z.

8. Irie $\mathrm{H}$, Okamoto $\mathrm{H}$, Uchino $\mathrm{S}$, Endo $\mathrm{H}$, Uchida $\mathrm{M}$, Kawasaki $\mathrm{T}$, et al. The Japanese Intensive care PAtient Database (JIPAD): a national intensive care unit registry in Japan. J Crit Care. 2019;55:86-94.https://doi.org/10.1016/j. jcrc.2019.09.004

9. Steyerberg EW. Clinical prediction models. 2nd ed. Springer Nature: Cham; 2019. https://doi.org/10.1007/978-3-030-16399-0.

\section{Publisher's Note}

Springer Nature remains neutral with regard to jurisdictional claims in published maps and institutional affiliations.
Ready to submit your research? Choose BMC and benefit from:

- fast, convenient online submission

- thorough peer review by experienced researchers in your field

- rapid publication on acceptance

- support for research data, including large and complex data types

- gold Open Access which fosters wider collaboration and increased citations

- maximum visibility for your research: over $100 \mathrm{M}$ website views per year

At BMC, research is always in progress.

Learn more biomedcentral.com/submissions 